\title{
Surgical treatment of active infective endocarditis: A continued challenge
}

Tirone E. David, MD, Gheorghe Gavra, MD, Christopher M. Feindel, MD, Tommaso Regesta, MD, Susan Armstrong, MSc, and Manjula D. Maganti, MSc

From the Division of Cardiovascular Surgery of Toronto General Hospital and University of Toronto, Toronto, Ontario, Canada.

Read at the Thirty-second Annual Meeting of the Western Thoracic Surgical Association, Sun Valley, Idaho, June 21-24, 2006.

Received for publication June 14, 2006; revisions received Aug 6, 2006; accepted for publication Aug 25, 2006.

Address for reprints: Tirone E. David, MD, 200 Elizabeth St, 4N-457, Toronto, Ontario M5G 2C4, Canada (E-mail: tirone.david@ uhn.on.ca).

J Thorac Cardiovasc Surg 2007;133:144-9

$0022-5223 / \$ 32.00$

Copyright (๑) 2007 by The American Association for Thoracic Surgery

doi:10.1016/j.jtcvs.2006.08.060
Objective: This study was undertaken to examine the outcomes of surgery for active infective endocarditis in a large cohort of patients.

Methods: Three hundred eighty-three consecutive patients underwent surgery for active infective endocarditis. The mean age was $51 \pm 16$ years, and $64 \%$ were men. The infected valve was native in 266 patients and prosthetic in 117. Staphylococcus aureus was the most common microorganism. Surgery consisted of valve replacement or repair in patients with infection limited to the cusps or leaflets of the valve or radical resection of seemingly infected paravalvular tissues, and reconstruction with patches and valve replacement in patients with abscess (135 patients). The mean follow-up was $6.1 \pm 5.2$ years.

Results: There were 45 (12\%) operative and 88 (23\%) late deaths. The operative mortality did not change during the period of study. Preoperative shock, prosthetic valve endocarditis, paravalvular abscess, and $S$ aureus were independent predictors of operative mortality. Age, shock, prosthetic valve endocarditis, left ventricular ejection fraction less than $40 \%$, and recurrent endocarditis were independent predictors of death from all causes. Survivals at 15 years were $44 \% \pm 5 \%$ overall, $59 \%$ $\pm 5 \%$ for native valve endocarditis, and $25 \% \pm 7 \%$ for prosthetic valve endocarditis $(P=.001)$. Freedom from recurrent endocarditis at 15 years was $86 \% \pm 3 \%$ for all patients, similar to those for native and prosthetic valve endocarditis $(P=.39)$. Freedom from reoperation at 15 years was $70 \% \pm 6 \%$ for all patients, similar to those for native and prosthetic valve endocarditis $(P=.55)$.

Conclusions: Surgery for endocarditis continues to be challenging and associated with high operative mortality and morbidity. Age, shock, prosthetic valve endocarditis, impaired ventricular function, and recurrent infections adversely affect longterm survival.

A ppropriate antibiotic therapy is the most important component in the treatment of patients with infective endocarditis. ${ }^{1}$ Depending on how promptly the disease is diagnosed and appropriate antibiotics are started, on the virulence of the microorganism, and on whether the infected valve is native or prosthetic, surgery may become indispensable to save the patient's life and eradicate the infection. Timing of surgery is crucial for patients for whom medical therapy fails. Delaying surgical treatment often increases the probability of complications and also operative mortality and morbidity. The notion that less virulent microorganisms, such as Streptococcus viridans, always respond to antibiotics alone is erroneous, because these bacteria can cause extensive damage to a heart valve and surrounding tissues if inadequately treated. ${ }^{2}$ Certain cases of infective endocarditis are deemed inoperable because of multiorgan failure or extensive cerebral damage from septic emboli, and these patients die of the disease. This study is a retrospective review of our experience with surgery for active infective endocarditis. 


\section{Abbreviations and Acronyms \\ $\mathrm{CI}=$ confidence interval \\ $\mathrm{HR}=$ hazard ratio \\ $\mathrm{OR}=$ odds ratio}

TABLE 1. Clinical characteristics of 383 patients with active infective endocarditis

\begin{tabular}{|c|c|}
\hline Characteristic & No. (\%) \\
\hline Age $(y$, mean $\pm S D)$ & $51 \pm 16$ \\
\hline Male & $247(64)$ \\
\hline \multicolumn{2}{|l|}{ Electrocardiogram } \\
\hline Sinus rhythm & $318(83)$ \\
\hline Atrial fibrillation & $54(14)$ \\
\hline Complete heart block & $11(3)$ \\
\hline \multicolumn{2}{|l|}{ Associated diseases } \\
\hline Diabetes mellitus & $44(11)$ \\
\hline Hypertension & $76(20)$ \\
\hline Chronic obstructive lung disease & $13(3)$ \\
\hline Renal failure & $42(11)$ \\
\hline Recent myocardial infarction $(<30 \mathrm{~d})$ & $11(3)$ \\
\hline Recent transient ischemic attack or stroke $(<30 \mathrm{~d})$ & $46(12)$ \\
\hline \multicolumn{2}{|l|}{ New York Heart Association functional class } \\
\hline I & $17(4)$ \\
\hline II & $11(3)$ \\
\hline III & $32(9)$ \\
\hline IV & $322(84)$ \\
\hline Cardiogenic or septic shock & $53(14)$ \\
\hline Native valve endocarditis & $266(69)$ \\
\hline Aortic valve & $94(35)$ \\
\hline Mitral valve & $77(29)$ \\
\hline Aortic and mitral valves & $74(28)$ \\
\hline Aortic and other valves & $9(3)$ \\
\hline Tricuspid valve & $11(4)$ \\
\hline Pulmonary valve & $1(1)$ \\
\hline Previous cardiac surgery & $129(34)$ \\
\hline Prosthetic valve endocarditis & $117(31)$ \\
\hline Aortic valve & $66(56)$ \\
\hline Mitral valve & $32(27)$ \\
\hline Aortic and mitral valves & $18(15)$ \\
\hline Pulmonary valve & $1(1)$ \\
\hline Left ventricular ejection fraction $<40 \%$ & $43(11)$ \\
\hline Coronary artery disease & $50(13)$ \\
\hline \multicolumn{2}{|l|}{ Timing of surgery } \\
\hline Same hospitalization & $206(54)$ \\
\hline Urgent or emergency & $177(46)$ \\
\hline
\end{tabular}

with unpaired $t$-test or nonparametric Wilcoxon test for continuous variables and $\chi^{2}$ test or Fisher exact test for categorical variables. The Kaplan-Meier method was used to calculate estimates for long-term survival or freedom from morbid events. The differences in longitudinal outcomes of native and prosthetic valve endocarditis were evaluated by using the log-rank statistic. The following perioperative variables were submitted to the multivariable model for Cox regression analysis to determine the independent multivariable predictors operative and late mortality: patient age by increments of 5 years, sex, atrial fibrillation, functional class, shock, renal failure, diabetes, recent stroke, previous valve surgery, coronary artery disease, left ventricular ejection fraction less than $40 \%$, valve infected, paravalvular abscess, $S$ aureus infection, timing of surgery, and type of valve implanted. Variable retention criteria in the model were set at a $P$ value of .05 . 
TABLE 2. Operative data

\begin{tabular}{lr}
\hline Operations performed & 160 \\
Aortic valve replacement & 93 \\
Mitral valve replacement & 16 \\
Mitral valve repair & 75 \\
Aortic valve replacement and mitral valve replacement & 26 \\
Aortic valve replacement and mitral valve repair & 11 \\
Tricuspid valve replacement & 2 \\
Pulmonary valve replacement & \\
Types of valves used & 214 \\
Mechanical & 133 \\
Bioprosthetic & 18 \\
Aortic homograft & 2 \\
Pulmonary homograft & 16 \\
Isolated mitral valve repair & \\
Additional procedures & 40 \\
Bentall procedure & 8 \\
Supracoronary replacement of ascending aorta & 42 \\
Reconstruction of left ventricular outflow tract & 49 \\
Reconstruction of mitral annulus & 19 \\
Repair of congenital ventricular septal defect & 2 \\
Repair of left ventricular aneurysm & 51 \\
Coronary artery bypass grafting &
\end{tabular}

\section{Results}

There were 45 operative deaths. Cause of deaths was often multifactorial, but the main reasons were multiorgan failure in 12 patients, low cardiac output syndrome in 8 , intractable sepsis in 5, coagulopathy in 5, technical errors in 4 , stroke in 4 , pulmonary embolism in 2 , acute myocardial infarction in 1 , ruptured aortic root in 1 , valve dehiscence in 1 , retroperitoneal bleeding in 1 , and right ventricular failure in 1. Table 3 shows the operative mortalities in various subgroups of patients. The operative mortality did not change during the period of study. Cox regression analysis identified preoperative shock (odds ratio [OR] 5.8, 95\% confidence interval [CI] 2.5-13.6), prosthetic valve endocarditis (OR 3.6, 95\% CI 1.6-8.0), $S$ aureus (OR 2.6, 95\% CI 1.1-6.0), and paravalvular abscess (OR 2.3, 95\% CI 1.3-4.2) as independent predictors of operative mortality.

Postoperative complications were common: 35 patients required reexploration of the chest for bleeding or tamponade; 20 patients had new strokes (14 intraoperative and 6 postoperative), 54 patients required permanent pacemaker for heart block, 20 required hemodialysis for new postoperative renal failure, and 2 had deep sternal infection develop. In addition, 6 patients required further valve surgery for valve dehiscence or persistent sepsis.

Eighty-eight patients died during the follow-up. The causes of deaths were cardiac in 51 patients (congestive heart failure in 14, recurrent endocarditis in 16, sudden cardiac death in 8 , myocardial infarction in 7 , stroke in 4 , and anticoagulation-related hemorrhage in 2), noncardiac in 32 , and unknown in 5. The 15-year survivals were $44 \% \pm$
TABLE 3. Operative mortalities in various subgroups

\begin{tabular}{lrcr}
\hline Variable & No. & $\begin{array}{c}\text { Operative } \\
\text { mortality (\%) }\end{array}$ & $\begin{array}{c}\boldsymbol{P} \\
\text { value }\end{array}$ \\
\hline Native valve endocarditis & 266 & 8.6 & \\
Prosthetic valve endocarditis & 117 & 18.8 & .004 \\
Prosthetic valve endocarditis & & & \\
$\quad$ Early ( $\leq 1$ y) & 39 & 25.6 & \\
$\quad$ Late & 78 & 15.4 & .033 \\
Preoperative shock & 53 & 35.8 & $<.001$ \\
Paravalvular abscess & 135 & 15.5 & .054 \\
Staphylococcus aureus & 87 & 17.2 & .070 \\
Preoperative renal failure & 42 & 26.2 & .002 \\
Recent transient ischemic & 45 & 16 & .112 \\
attack or stroke & & & \\
Ejection fraction $<40 \%$ & 43 & 14 & .095 \\
Timing of surgery & & & \\
$\quad$ Same hospitalization & 206 & 7.8 & \\
$\quad$ Urgent or emergency & 177 & 16.4 & .003 \\
Valve infected & & & \\
$\quad$ Aortic valve & 160 & 10 & \\
$\quad$ Mitral valve & 109 & 11 & \\
$\quad$ Aortic and mitral valves & 92 & 14 & \\
$\quad$ Other valves & 22 & 18 & \\
\hline & & & \\
& & &
\end{tabular}

$5 \%$ for all patients, $59 \% \pm 5 \%$ for patients with native valve endocarditis, and $25 \% \pm 7 \%$ for patients with prosthetic valve endocarditis $(P=.001)$. Figure 1 compares the survivals of patients with native and prosthetic valve endocarditis. Cox regression analysis identified age by 5 -year increment (hazard ratio [HR] 1.15, 95\% CI 1.07-1.24), prosthetic valve endocarditis (HR 1.8, 95\% CI 1.2-2.7), left ventricular ejection fraction less than $40 \%$ (HR 1.8, 95\% CI 1.1-2.7), recurrent endocarditis (HR 2.2, 95\% CI 1.2-3.9), and shock (HR 2.5, 05\% CI 1.6-4.0) as independent predictors of death from all causes.

Recurrent endocarditis occurred 34 times in 32 patients: 10 during the first postoperative year and 22 in subsequent years. The offending microorganism was the same as in the first infection in 8 instances, different in 22 , and culture

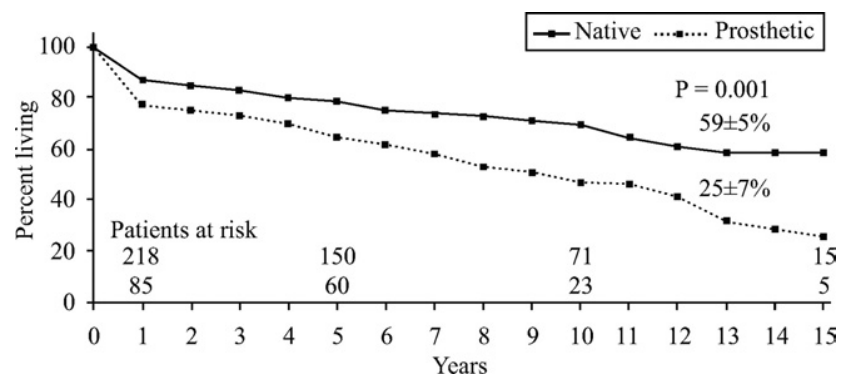

Figure 1. Long-term survival of patients with native and prosthetic valve endocarditis. 


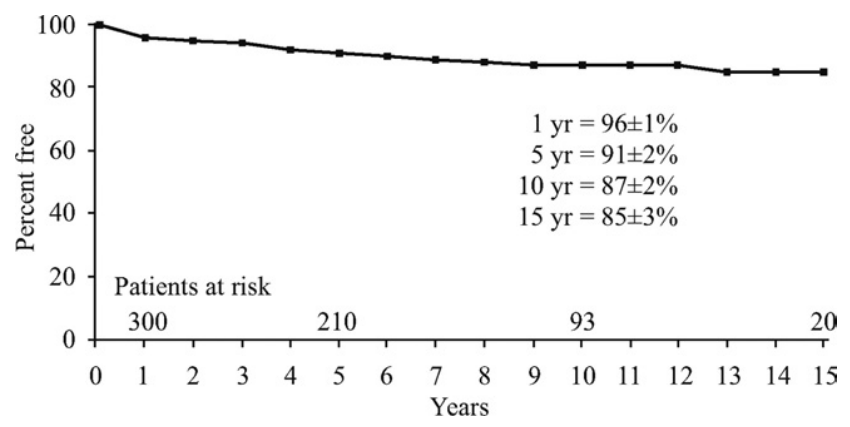

Figure 2. Freedom from recurrent infective endocarditis for all patients.

negative in 4 . Ten patients were operated on ( 2 patients had 2 reoperations each), with 1 death, and 22 patients were treated with antibiotics alone, with 15 deaths. Figure 2 shows the freedom from recurrent infective endocarditis for all patients. The 15-year freedoms from recurrent endocarditis were $86 \% \pm 3 \%$ for all patients, $84 \% \pm 4 \%$ for patients who had surgery for native valve endocarditis, and $90 \% \pm 4 \%$ for those with prosthetic valve endocarditis $(P$ $=.39$ ). The type of valve implanted had no effect on the risk of recurrent endocarditis.

There were 36 reoperations in 34 patients: 12 for bioprosthetic valve failure, 12 for recurrent infective endocarditis, 7 for valve dehiscence without endocarditis, 2 for recurrent mitral regurgitation after mitral valve repair, 1 for mechanical valve dysfunction, 1 for a false aneurysm of the aortic root, and 1 for aortic dissection. Figure 3 shows the freedom from reoperation for all patients. The 15 -year freedoms from reoperation were $70 \% \pm 6 \%$ for all patients, $66 \% \pm 7 \%$ for patients with native valve endocarditis, and $84 \% \pm 5 \%$ for patients with prosthetic valve endocarditis $(P$ $=.55$ ).

Other valve-related complications were primary tissue failure of bioprosthetic valves in 12 patients, prosthetic

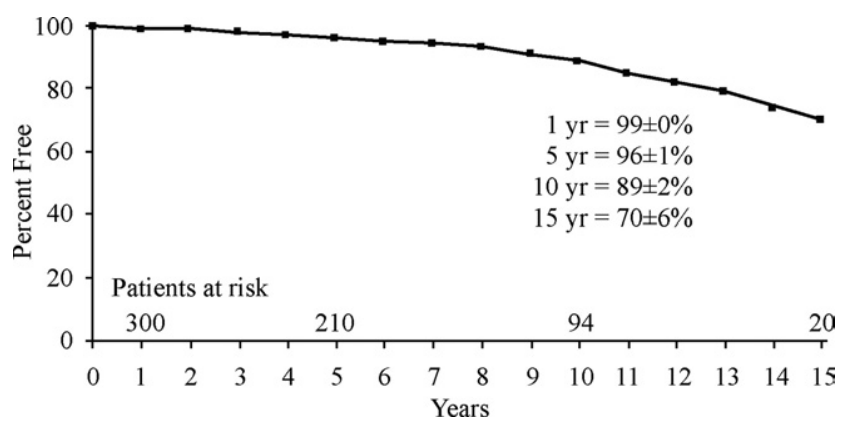

Figure 3. Freedom from reoperation for all patients. valve dehiscence in 12 , thromboembolism in 22 , and major anticoagulation-related hemorrhage in 3 .

At the latest follow-up contact, 216 patients were alive and free from reoperation: 160 (74\%) were in New York Heart Association functional class I, 35 (16\%) were in class II, and $21(10 \%)$ were in class III.

\section{Discussion}

This report describes the early and late outcomes of surgery for active infective endocarditis in a large cohort of patients during a 27-year interval. Although we are aware of a few patients with disease deemed inoperable during this period, their number was very small. Indeed, in our series, $14 \%$ of the patients were moribund when taken to the operating theater. Thus the operative mortality and morbidity in this report probably reflect an accurate risk of surgery in patients with active infective endocarditis in a large tertiary care hospital.

The operative mortality for active infective endocarditis did not change during the past two decades in our institution. A stepwise logistic regression analysis identified preoperative shock, prosthetic valve endocarditis, paravalvular abscess, and endocarditis caused by $S$ aureus as independent predictors of operative mortality. Thus to reduce operative mortality, these variables would have to be modified, although this would not be always possible. For instance, most of our patients were treated initially in other hospitals, and we had no input regarding the medical management. They were referred for surgery only after medical therapy failed; often they were in intractable heart failure, and sometimes they had multiorgan dysfunction. Although cardiac surgery is necessary in fewer than a third of patients who have infective endocarditis of native valves and fewer than half of those with prosthetic valves, ${ }^{6-9}$ a multidisciplinary approach is necessary to treat these patients and must involve at least specialists in infectious disease, cardiology, and cardiac surgery. ${ }^{10}$ The indications for and timing of surgery are still controversial among internists who treat these patients, and the input of a cardiac surgeon is needed if mortality and morbidity are to be reduced. ${ }^{10,11}$ Close surveillance of these patients is indispensable to detect early failure of adequate antibiotic therapy to avoid cardiogenic or septic shock and multiorgan failure.

It has been shown that cases of endocarditis caused by $S$ aureus and other virulent microorganisms on valves in the left side of the heart are best treated with early surgery..$^{10-12}$ In a large merged database on native valve endocarditis, the overall mortality was higher among patients with $S$ aureus endocarditis than among those with other bacteria (20\% vs $12 \%, P=.001$ ); surprisingly, however, fewer patients infected with $S$ aureus had surgery (26\% vs. $39 \%, P=$ .001). ${ }^{12} S$ aureus emerged as an independent predictor of operative mortality in our surgical series. The operative 
mortality among patients with $S$ aureus endocarditis was $17 \%$, whereas that for all other bacteria was $10 \%$.

The outcomes of prosthetic valve endocarditis are worse than those of native valve endocarditis. ${ }^{9-11}$ We found that not only was prosthetic valve endocarditis associated with higher operative mortality, but also it adversely affected long-term survival relative to native valve endocarditis. The operative mortality for prosthetic valve endocarditis was $17.5 \%$ in our series. The mortalities in published series have varied widely. In a report from the United Kingdom Heart Valve Registry on 322 cases of prosthetic valve endocarditis, the 30-day mortality was $20 \%$ and the 5- and 10-year survivals were $55 \%$ and $37 \%$, respectively. ${ }^{13}$ Investigators from the Cleveland Clinic reported an operative mortality of $13 \%$ among 146 patients with prosthetic valve endocarditis; among those who survived surgery, the 5-year survival was $82 \%$ and the freedom from reoperation was $75 \%{ }^{14}$ In another report from the same institution on prosthetic aortic valve endocarditis treated exclusively with aortic valve homograft, the operative mortality was only $3.9 \%$ and the 5and 10 -year survivals were $73 \%$ and $56 \%$, respectively. ${ }^{15}$

The main reason the operative mortality for prosthetic valve endocarditis is higher than that for native valve endocarditis is the complexity of the operation and the fact that it is often associated with paravalvular abscess. Resection of aortic root abscess is indeed a complex operation, but resection of mitral annulus abscess can be even worse. ${ }^{2-5}$ Although aortic valve homografts are believed to be the best valve for aortic root abscess, ${ }^{15,16}$ they are not a substitute for radical débridement and implantation of the new valve on healthy and strong tissues. ${ }^{2}$ Persistent or early recurrent endocarditis is probably related more to the surgeon's recognition of and ability to extirpate all infected tissues than to the type of valve used for replacement. ${ }^{2}$ We believe that aortic homograft is ideally suited for reconstruction of the aortic root, however, because it is easier to handle than prosthetic materials and its anterior leaflet of the mitral valve can be used to patch defects created by the resection of the abscess. Although there is a lot of information on surgery for aortic root abscess, ${ }^{15,16}$ there is little on mitral annulus abscess or on patients with combined mitral and aortic valve abscesses. ${ }^{2,17,18}$ Resection of abscess in the posterior mitral annulus, in the intervalvular fibrous body, or both is a formidable operative procedure associated with high operative mortality, but we believe that it is the only way to eradicate the infection and provide satisfactory longterm results. ${ }^{3,19}$

Some surgeons believe that aortic valve homograft may reduce operative mortality and risk of reinfection in aortic valve endocarditis. ${ }^{15-17}$ Others question its superiority. ${ }^{2,20}$ The reality is that valve homograft is seldom used in mitral valve endocarditis ${ }^{17}$ and is not used in aortic valve endocarditis as frequently as are mechanical and bioprosthetic valves in most series. ${ }^{6,13,14,20,21}$ The risk of recurrent endocarditis is similar for mechanical and bioprosthetic valves. ${ }^{21}$ Given the complexity of some of these operations, we tend to use more mechanical than bioprosthetic valves, particularly in younger patients.

Despite perioperative problems in treating patients with infective endocarditis, the long-term survival is satisfactory, particularly for patients with native valve endocarditis. The 15-year survival in our series was $59 \%$, similar to that reported by Stanford University. ${ }^{21}$ The 15 -year survival among patients with prosthetic valve endocarditis was only $25 \%$, also similar to that of Stanford University. ${ }^{21}$ The reasons for the differences in long-term survival between native and prosthetic valve endocarditis are likely multifactorial and include higher operative mortality, more complex operations, and such patient variables as older age and worse ventricular function.

The rates of reoperation among patients who undergo surgery for active infective endocarditis appear to be only slightly higher than those among patients with prosthetic valves who never had endocarditis, but the rates of recurrent infection are significantly increased. This suggests that a predisposing factor in addition to the prosthetic valve plays a role in the development of endocarditis in certain patients. ${ }^{22,23}$

In conclusion, surgery for active infective endocarditis continues to be challenging and to be associated with high operative mortality and morbidity. The long-term survival is satisfactory, although these patients are at higher risk for development of recurrent endocarditis than are patients who have never had valve infection.

\section{References}

1. Mylonakis E, Calderwood SB. Infective endocarditis in adults. $N$ Engl J Med. 2001;345:1318-30.

2. d'Udekem Y, David TE, Feindel CM, Armstrong S, Sun Z. Long-term results of operation for paravalvular abscess. Ann Thorac Surg. 1996; 62:48-53.

3. David TE, Kuo J, Armstrong S. Aortic and mitral valve replacement with reconstruction of the intervalvular fibrous body. J Thorac Cardiovasc Surg. 1997;114:766-71.

4. David TE, Feindel CM, Armstrong S, Sun Z. Reconstruction of the mitral anulus. A ten-year experience. J Thorac Cardiovasc Surg. 1995;110:1323-32.

5. David TE, Komeda M, Brofman PR. Surgical treatment of aortic root abscess. Circulation. 1989;80:I269-74.

6. d'Udekem Y, David TE, Feindel CM, Armstrong S, Sun Z. Long-term results of surgery for active infective endocarditis. Eur J Cardiothorac Surg. 1997;11:46-52.

7. Heiro M, Helenius H, Makila S, Hohenthal U, Savunen T, Engblom E, et al. Infective endocarditis in a Finnish teaching hospital: a study on 326 episodes treated during 1980-2004. Heart. 2006;92:1457-62.

8. Cabell CH, Abrutyn E, Fowler VG Jr, Hoen B, Miro JM, Corey GR, et al. Use of surgery in patients with native valve infective endocarditis: results from the International Collaboration on Endocarditis Merged Database. Am Heart J. 2005;150:1092-8.

9. Wang A, Pappas P, Anstrom KJ, Abrutyn E, Fowler VG Jr, Hoen B, et al. The use and effect of surgical therapy for prosthetic valve infective endocarditis: a propensity analysis of a multicenter, international cohort. Am Heart J. 2005;150:1086-91. 
10. Moreillon P. Infective endocarditis. Lancet. 2004;363:139-49.

11. Hill EE, Hurijgers P, Herregods MC, Peetermans WE. Evolving trends in infective endocarditis. Clin Microbiol Infect. 2006;12:5-12.

12. Miro JM, Anguera I, Cabell CH, Chen AY, Stafford JA, Corey GR, et al. Staphylococcus aureus native valve infective endocarditis: report on 566 episodes from the International Collaboration on Endocarditis Merged Database [published erratum appears in Clin Infect Dis. 2005; 41:1075-7]. Clin Infect Dis. 2005;41:507-14.

13. Edwards MB, Ratnatung CP, Dore CJ, Taylor KM. Thirty-day mortality and long-term survival following surgery for prosthetic endocarditis: a study from the UK heart valve registry. Eur J Cardiothorac Surg. 1998;14:156-64.

14. Lytle BW. Surgical treatment of prosthetic valve endocarditis. Semin Thorac Cardiovasc Surg. 1995;7:13-9.

15. Sabik JF, Lytle BW, Blackstone EH, Marullo AG, Pettersson GB, Cosgrove DM. Aortic root replacement with cryopreserved allograft for prosthetic valve endocarditis. Ann Thorac Surg. 2002;74:650-9.

16. Yankah AC, Pasic M, Klose H, Siniawski H, Weng Y, Hetzer R. Homograft reconstruction of the aortic root for endocarditis with periannular abscess: a 17-year study. Eur J Cardiothorac Surg. 2005; 28:69-75.

17. Obadia JF, Henaine R, Bergerot C, Ginon I, Nataf P, Chavanis N, et al. Monobloc aorto-mitral homograft or mechanical valve replacement: a new surgical option for extensive bivalvular endocarditis. J Thorac Cardiovasc Surg. 2006;131:243-5.

18. Siniawski H, Grauhan O, Hofmann M, Pasic M, Weng Y, Yankah C, et al. Aortic root abscess and secondary infective mitral valve disease: results of surgical endocarditis treatment. Eur J Cardiothorac Surg. 2005;27:434-40.

19. de Oliveira NC, David TE, Armstrong S, Ivanov J. Aortic and mitral valve replacement with reconstruction of the intervalvular fibrous body: an analysis of clinical outcomes. J Thorac Cardiovasc Surg. 2005; 129:286-90.

20. Hagl C, Galla JD, Lansman SL, Fink D, Bodian CA, Spielvogel D, et al. Replacing the ascending aorta and aortic valve for acute prosthetic valve endocarditis: is using prosthetic material contraindicated? Ann Thorac Surg. 2002;74:S1781-5; discussion S1792-9.

21. Moon MR, Miller DC, Moore KA, Oyer PE, Mitchell RS, Robbins $\mathrm{RC}$, et al. Treatment of endocarditis with valve replacement: the question of tissue versus mechanical prosthesis. Ann Thorac Surg. 2001;71:1164-71

22. Borger MA, Ivanov J, Armstrong S, Christie-Hrybinsky D, Feindel CM, David TE. Twenty-year results of the Hancock II bioprosthesis. J Heart Valve Dis. 2006;15:49-55.

23. Emery RW, Krogh CC, Arom KV, Emery AM, Benyo-Albrecht K, Joyce LD, et al. The St. Jude Medical cardiac valve prosthesis: a 25-year experience with single valve replacement. Ann Thorac Surg. 2005;79:776-82.

\section{Discussion}

Dr Steven W. Guyton (Seattle, Wash). Thank you, Dr Gavra, for an excellent presentation and for the opportunity to review your manuscript before the meeting.

Active endocarditis that cannot be managed with antibiotic therapy alone is a devastating problem, as you have so well illustrated. You might illustrate this as well by including a graph indicating the freedom from mortality and morbidity-reoperation, recurrent endocarditis, thromboembolism, stroke, heart block, renal failure, sternal infection, and others. I anticipate that close to $100 \%$ of your patients will show complications during your 10- to 15-year follow-up. I agree with your emphasis on aggressive débridement of all infected tissue and less emphasis on the type of prosthesis. The prostheses you used were approximately 2:1 mechanical versus bioprosthetic and then some homografts. Have you seen a difference in outcomes depending on your choice of prosthesis, and what is your preference at present?
Dr Gavra. I am not the senior surgeon, but I can assure you that Dr David's approach is to excise all infected tissues to allow implantation of a prosthetic valve in healthy and strong tissues. He believes that the outcomes for patients with paravalvular abscess is influenced more by the surgeon's ability to recognize and extirpate all infected tissue than by the type of prosthetic valve implanted.

Dr Guyton. Did you look at the outcomes, though, related to the type of prosthesis that was used as to whether your data showed any difference?

Dr Gavra. No.

Dr Guyton. Recurrent endocarditis treated medically had a dismal prognosis, with a $75 \%$ mortality reported in the manuscript. Homografts have been touted as more resistant to recurrent infection. Is this an argument for the use of homografts?

Dr Gavra. With respect to the patients who had recurrent endocarditis, I'd have to say that the 22 patients who were treated with antibiotics only were treated elsewhere, not in Toronto General Hospital and they didn't benefit from surgery. I would suppose this to be one of the reasons that mortality is so high for this subgroup of endocarditis.

Dr Guyton. Thank you for that clarification. Ten percent of your patients were operated on for large vegetations. This is the first time I have seen this as an indication for surgery from your group. Why were operations performed for vegetation size? I know my cardiologists get skittish about these vegetations, but I've not been convinced that operating for the size of vegetations is appropriate.

Dr Gavra. Because of fear of embolization, vegetations larger than $10 \mathrm{~mm}$ in diameter were considered an indication for surgery.

Dr Guyton. I think we might want to be very careful about using that as an indication for surgery. In the medical literature, there is encouragement for shorter durations of antibiotic treatment, which I have found disturbing in this population of patients given the consequences of treatment failure. I note that you reported freedom from recurrent endocarditis to be better after prosthetic valve endocarditis. Were these patients treated differently because they already had prosthetic valves, and what is your standard course of antibiotic therapy?

Dr Gavra. The patients in this study received intravenous antibiotics for a total of 6 weeks. Although my slide showed a lower risk of recurrent endocarditis among patients with prosthetic valve than in those with native valve endocarditis, the difference was not statistically significant.

Dr Guyton. In $S$ aureus infection timing of operation is important. As a tertiary referral center, you did not always have control over when the operation occurred relative to the date of presentation. In analyzing the data, did you find a difference in outcomes depending on when the patient was operated on versus the time of presentation?

Dr Gavra. Although the overall mortality among patients with $S$ aureus endocarditis was higher than that among those with other bacteria, I don't know whether timing of surgery played a role in the outcome.

Dr Guyton. Having that analysis might help us evaluate the data a little bit more extensively. Thank you for opportunity to review the manuscript and to discuss this presentation.

Dr Gavra. Thank you very much, Dr Guyton. 